\title{
DEVELOPMENT OF A METHOD AND INSTRUMENTS TO ASSESS THE BUILD QUALITY AND THE TECHNICAL CONDITION OF AN ELECTRIC GEAR ACTUATOR FOR AN ELECTROMECHANICAL ORTHOSIS OF A LOWER LIMB EXOSKELETON
}

\author{
Vladimir Belogusev*, Aleksey Egorov \\ Institute of Mechanics and Machine Building, Volga State University of Technology, Russian Federation
}

This paper proposes a method and instruments for assessing the build quality and the technical condition of an electric gear actuator for an exoskeleton based on determining its starting torque as one of the main indicators of the level of degradation of its components. Existing methods are mainly based on identifying starting torque with the help of additional devices that require involvement of an operator in the measurement process, which increases its time and labor costs and makes it difficult to be automated. As opposed to the existing methods and instruments, the method and hardware-software complex developed in this study allow automating the measurement process, does not require expensive equipment, and has potential for conducting technical state control without dismounting an actuator from an exoskeleton. In the experimental part of this paper, the proposed method and tools were evaluated on the basis of electric actuators with reduction gears for an electromechanical orthosis of a lower limb exoskeleton. According to the experimental results, the discrepancy between the values of starting torque obtained separately by an existing method and by the proposed one is within $1.8 \%$, which confirms the efficacy and applicability of the developed method for monitoring the technical condition of electric actuators for exoskeletons both at the stage of their production and during their operation.

Keywords: Starting torque, Reduction gear-motor, Exoskeleton efficiency control, Electric drive efficiency, Exoskeleton actuator

\section{INTRODUCTION}

In the past few decades, significant progress has been made in the development of exoskeletons, which are mobile bionic devices that expand human capabilities and facilitate physical activity by providing active or passive help to the muscles of the body [1-3]. Their use has become noticeable in many areas of human life [4-6], especially in medicine $[7,8]$, where exoskeletons allow people with impaired musculoskeletal functions gaining the ability to move independently performing everyday tasks $[9,10]$. Compared to traditional physical therapy, auxiliary rehabilitation with an exoskeleton has several advantages, which consist in reducing the working time of therapists, allowing a patient to conduct intensive rehabilitation trainings and providing a quantitative assessment of the level of recovery by measuring strength and movement patterns [2,11,12].

Along with the relevance and usefulness of an exoskeleton in a person's life, for a developer and a manufacturer such a multifunctional robotic system is an extremely complex and critical device that requires ensuring a high level of build quality and timely maintenance [13-15]. In this regard, great attention should be paid to monitoring the technical condition of main components subjected to increased and alternating loads, and failure of which can lead to detrimental consequences for human health and his environment $[2,16]$.
Currently, the main operation units that support the motion of human joints and transmit torque to the wearer's controlled limbs are electric actuators [17-19]. These devices, in particular, those with involute gears, which have a greater specific power, are made with a large number of friction nodes and high-precision elements, and, therefore, even minor damage or departure from the desired level of their build quality lead to an increased rate of degradation processes, backlashes and jams, which have a significant impact on their service life $[20,21]$. Therefore, the use of modern methods and tools to control their technical condition providing high measurement accuracy and low level of time costs is an important task in the quality improvement and safe operation of exoskeletons.

When choosing methods and tools for assessing the build quality and the technical condition of electric gear actuators, special attention should be paid to the possibility of determining the indicators characterizing the level of degradation processes in their separate components, which are mostly influenced by the frictional forces. One of such indicators is starting torque, which in a number of scientific papers is defined as one of the most important indicators of the quality of assembly and the technical state of rotating mechanisms [22-24].

Currently, the determination of the starting torque of an electric gear actuator is carried out both on an input and on an output links of a reducer $[25,26]$. The most prefer 
able method is to identify the starting torque on an input link, since it has a direct effect on an electric motor. There are, in turn, two main methods for determining the starting torque on an input link. According to the first one [26], the measurement is reduced to the determination of the force of gravity created by calibrated weights, which are used to overcome the static moment of friction in nodes of an actuator. The second method [25] is more accurate and differs from the first one in that the measurement of the force required to overcome the friction forces is carried out using a spring dynamometer. The main disadvantages of both methods are high requirements for accuracy of conducting experiments and their complexity. As for the output link starting torque, it is measured when it is not possible to take measurements on an input link of a reducer (when dismounting a reducer causes considerable difficulties). For example, in Nabtesco Reducers, the output link starting torque is reduced to the input link one using a reduction ratio. The main disadvantage of this method is the neglect of the reducer efficiency in the measurements.

Based on the analysis of existing methods and instruments for identifying the starting torque of an electric gear actuator, it can be concluded that they either have insufficient measurement accuracy or require significant labor and time resources, which impedes the accelerated test of an actuator during its operation and on-condition maintenance. In addition, the improvement of existing methods in terms of automating the measurement process is a laborious task due to the presence of a large number of factors affecting the measurement result.

The purpose of this paper is the development and experimental evaluation of a new method and instruments for measuring the starting torque of electric gear actuators for exoskeletons, which do not have the shortcomings inherent in existing methods and tools. Approbation of the proposed approach is supposed to be carried out on the basis of an electric actuator for an electromechan-

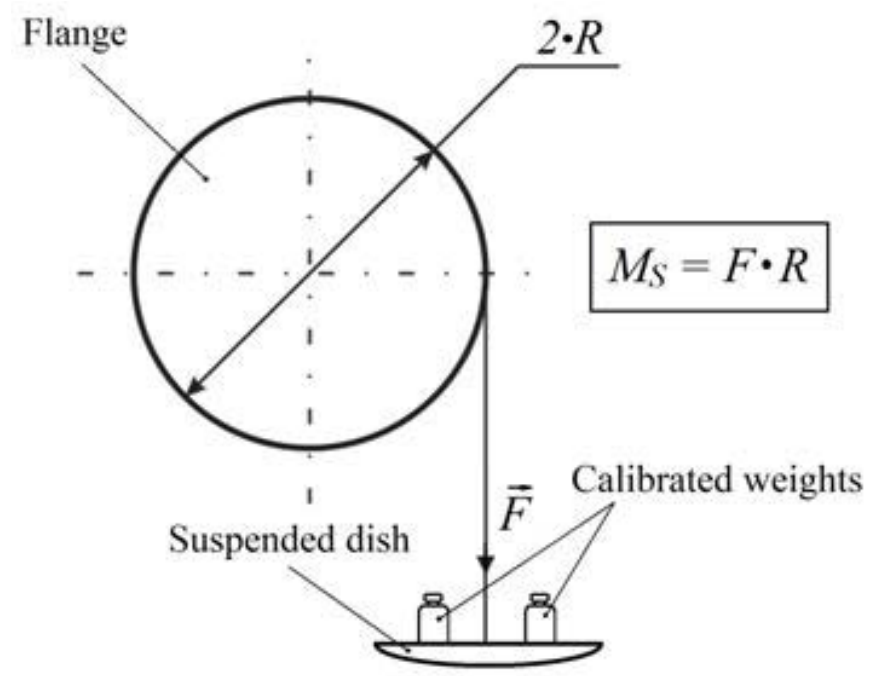

Figure 1: Scheme of imposition of forces to determine the starting torque of an electric drive using an existing method ical orthosis of a lower limb exoskeleton developed in the laboratory Mechatronic Systems of the Volga State University of Technology.

\section{THEORY AND METHODS}

\section{Description of a new method for determining the starting torque of an electric gear actuator}

As noted above, one of the main indicators that assess the build quality of electric actuators for exoskeletons is the starting torque, which characterizes the level of friction between their elements.

To clarify the gist of the method proposed in this paper for determining starting torque, it is necessary to draw an analogy with the sequence of actions that are performed when determining it using an existing method.

Fig. 1 shows the scheme of implementation of the method, which is widely used at present.

According to the presented scheme, to determine the starting torque of an actuator, MS, an input link of a reducer attached to an additional flange is being loaded with a force, $F$, through the arm, $R$, which equals to the radius of the flange, until the starting torque, MS, overcomes the force of internal friction of the actuator, as a result of which it starts rotating. In this case, the force, $F$, is created by calibrated weights suspended by a strand wrapped around the flange. Thus, the static moment of friction in the units of the electric actuator is overcome by the gravity of those weights.

On the other hand, overcoming the friction forces in the units of the electric actuator is possible with the help of its electric motor. Depending on the level of friction, to start rotating the system, the electric motor needs to consume a certain amount of energy, an indicator of which can be the current (starting current), which varies depending on the level of friction. This approach minimizes the impact of the human factor, is less time consuming, and allows assessing the build quality of an electric gear actuator and a reducer in an automatic mode, which contributes to its use not only at their assembly stage, but also at the stage of their operation.

The scheme of implementation of the method developed in this paper is presented in Fig. 2.

At the first stage, with the help of an electric motor 5 , an input link 3 of a reducer 2 is driven into rotation. A current sensor registers the current value when the input link 3 turns through a predetermined angle, $\alpha$, which is equal to the first stage starting point of rotation. The angles of rotation of the input link 3 of the reducer 2 (electric motor output shaft) are determined using an absolute encoder 4 , which is included in the test actuator. The rotation of the electric motor 5 is stopped when the predetermined angle, $\Delta$, taken as the first stage ending point of rotation, is reached. 


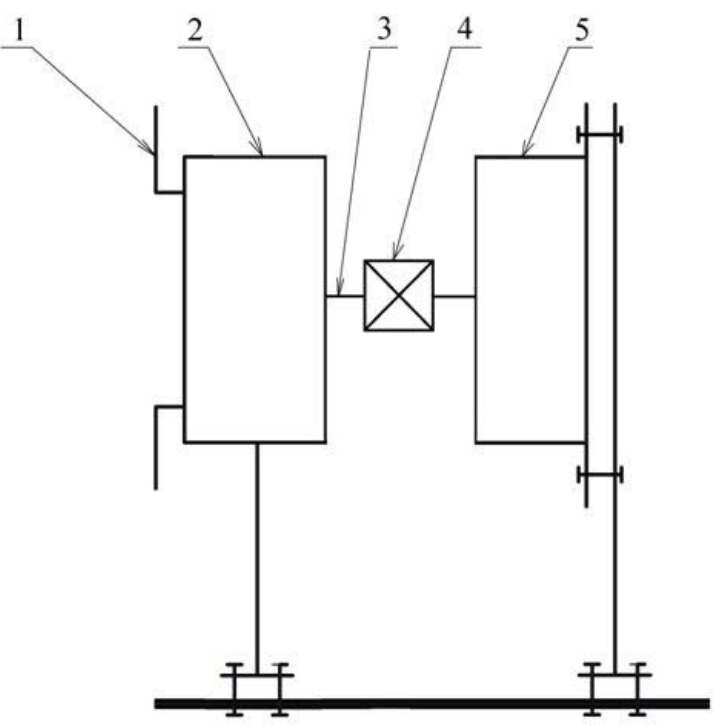

1 is an output link of a reducer; 2 is a reducer; 3 is an input link of a reducer; 4 is an absolute encoder; 5 is an electric motor

Figure 2: Scheme of implementation of a new method for determining the starting torque of an electric gear actuator

This angle is defined as the increment of rotational angle and calculated according to the following equation:

$$
\Delta=\frac{360}{i}
$$

Where, $\mathrm{i}$ is a reduction ratio.

That was the end of the first stage out of $\mathrm{N}$ ones of starting current identification. Then, after the electric motor 5 stops, with a certain time delay, the process of measuring the current continues. At the second stage, the input link 3 is driven into rotation again. A current sensor registers the current value when the input link 3 turns through the angle $\alpha$ and reaches the second stage starting point of the reducer input link 3, which is determined as follows:

The rotation of the electric motor 5 is stopped when the

$$
\beta=\alpha+\frac{360}{i}
$$

angle $2 \Delta$, taken as the second stage ending point of rotation, is reached.

Measurements of the current continue until the input link 3 of the reducer 2 makes i revolutions, which corresponds to one complete revolution of its output link 1 . The calculated increment, $\Delta$, allows completing the measurement process in the initial point of the rotation of the output link 1 of the reducer 2 .

The number of stages of the starting current measurement can be determined according to the following equation:

$$
N=i^{2}
$$

Thus, during the test of an electric gear actuator according to the proposed approach, it operates in the intermittent mode, which allows determining the starting currents at different angles of rotation of an output link of a reducer. At the same time, having determined the coefficient that determines the dependence of starting torque on starting current of an electric motor (specified in the motor certificate data or calculated experimentally), it is possible to determine the starting torque of an actuator on the basis of its starting current, and, therefore, assess its build quality and technical condition during operation. It should be noted that the specified increment of rotational angle, $\Delta$, does not allow completely covering the entire rotational range of a reducer and an electric actuator. Therefore, an additional stage of the developed method is to measure the change in current when rotating an electric actuator steadily without interruptions. The speed of rotation is selected on the basis of a predetermined maximum permissible value of starting current. Thus, when exceeding this value above the tolerance, it is possible to detect an unacceptable increase in the level of friction in the units, and, consequently, to define the technical condition of an electric actuator as unsatisfactory.

\section{Block diagram of the implementation of a new meth- od for assessing the build quality and the technical condition of an electric gear actuator}

Fig. 3 presents the block diagram of the implementation of the developed method for assessing the technical condition and the build quality of an electric gear actuator for an electromechanical orthosis of a lower limb exoskeleton.

In the course of statistical treatment of the starting torque values, the sampling variance, the standard deviation, the absolute and relative errors of measurement results at a given confidence level are determined, and blunders that are to be excluded from the sample are found. Based on the results obtained, a decision on the permissibility of the further use of an actuator is made.

\section{EXPERIMENTAL SETUP}

To evaluate the proposed method for assessing the technical condition and the build quality of an electric gear actuator for an electromechanical orthosis of a lower limb exoskeleton, a hardware-software complex was developed (Fig. 4).

With the help of the presented hardware and software complex, the rotation angles of an input link of a reducer and the currents (starting currents) were registered. Based on the data measured by the developed complex, the instantaneous and average values of the desired quantities were determined.

An absolute magnetic encoder with SSI interface was used to measure the rotational angles of an input link of a reducer. Structurally, it is an electronic chip with a small 


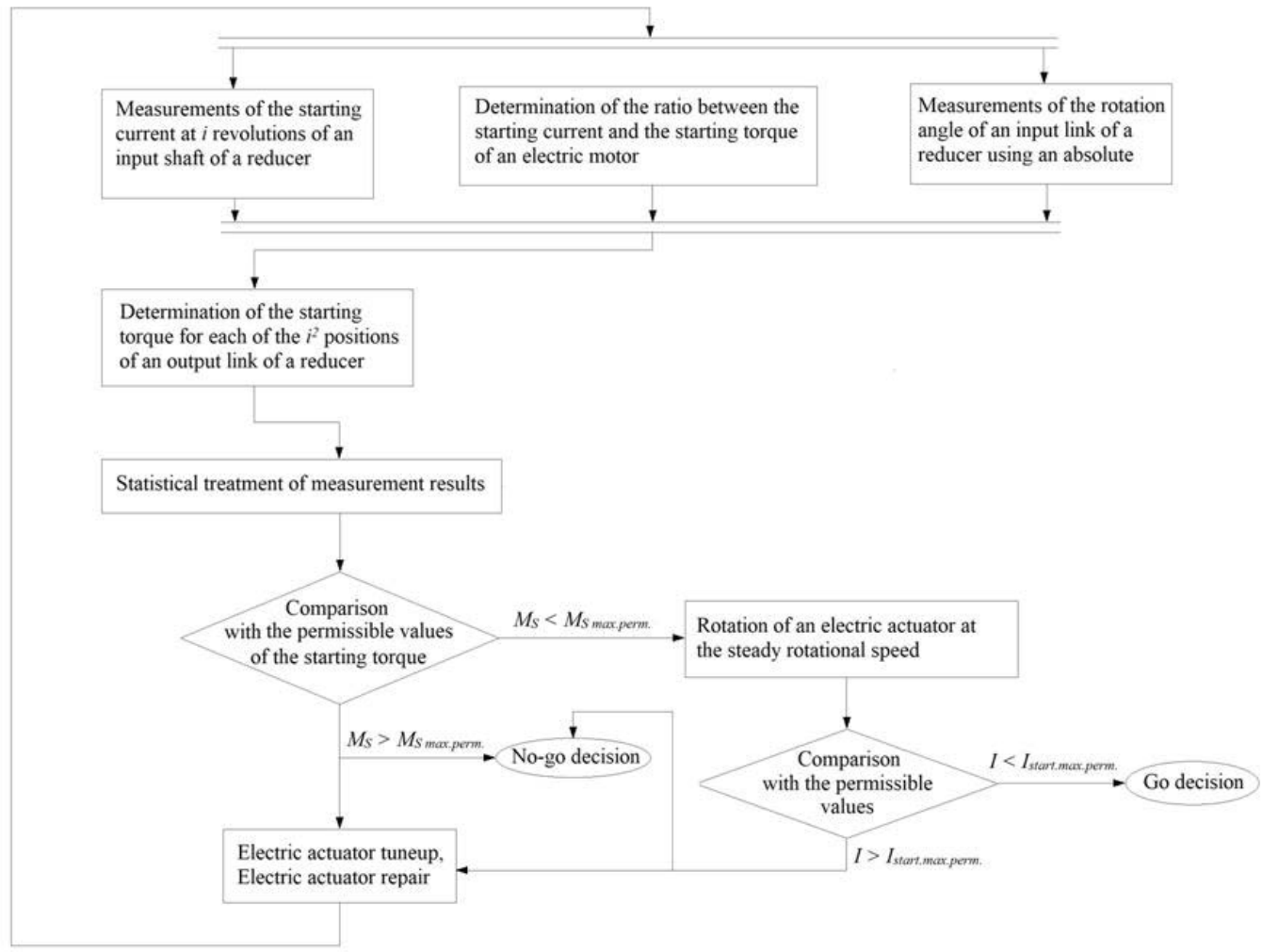

Figure 3: Block diagram of the implementation of the developed method for assessing the technical condition and the build quality of an electric gear actuator for an electromechanical orthosis of a lower limb exoskeleton

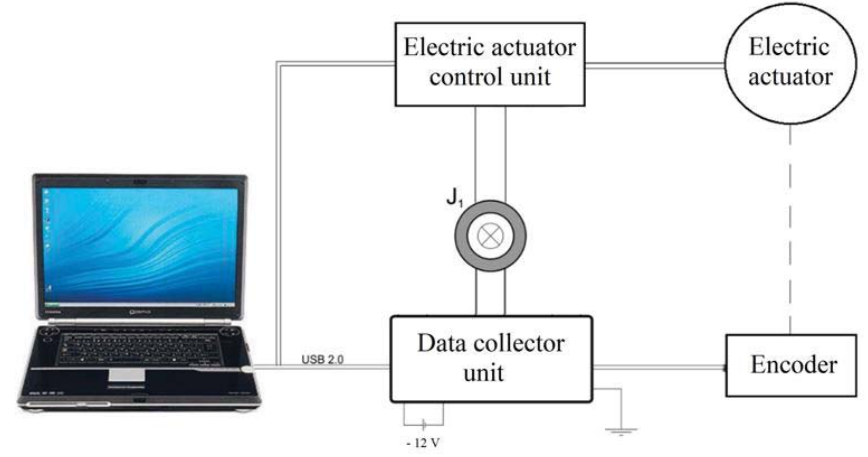

Figure 4: The structure of the hardware-software complex to control the starting torque of an electric gear actuator at different angles of rotation of an output link of a reducer

number of auxiliary components and a permanent magnet rotating very close to the chip. When turning, a magnet provides an alternating magnetic field caught by the Hall sensor. The Hall sensor is made using MEMS technology and is integrated into the encoder chip. The used AS5040 microcircuit encoder is capable of operating in the absolute encoder mode. This allows it to be used on an input link of a reducer for precise control of the absolute position of a reducer shaft. The encoder form factor is a compact round board built into an electric actuator.

A low-impedance shunt was used as a current sensor. The hardware-software complex has one analog measuring channel (for a low-resistance shunt) and one digital measuring channel (for an encoder). Digital and analog signals from the sensors are fed to an input of a data collector, in which they enter a measuring microcontroller Atmega 640 with a clock frequency of $16 \mathrm{MHz}$ through a galvanic separation of signals and a filter (Fig. 5). The galvanic separation system consists of two units, which are a power separation and a signal line separation. The digital signal from the microcontroller enters a flash memory until the end of the measurement. After the measurement is completed, the data from the flash memory is transferred to a personal computer (PC) and processed by a terminal program installed on a PC hard disk.

In the terminal program on the $\mathrm{PC}$, mathematical processing of the data array is carried out, currents and starting torques are determined for each angle of rotation of an output link of a reducer, and their comparison with the permissible levels of values is implemented.

An electric actuator is driven by EC 90 electric motor made by Maxon Motors company. These electric motors are characterized by high efficiency and compact flat design.

In order to be able to automatically measure starting torques, a high-speed control panel was developed, which consisted of a debugging board ESCON Module Motherboard and a high-performance controller ESCON Module 50/5. For the ESCON Module 50/5 driver, a software Escon Studio was used, which allowed creating various options of control algorithms, for example, maintaining uniform speed at the final stage of the electric actuator test. 


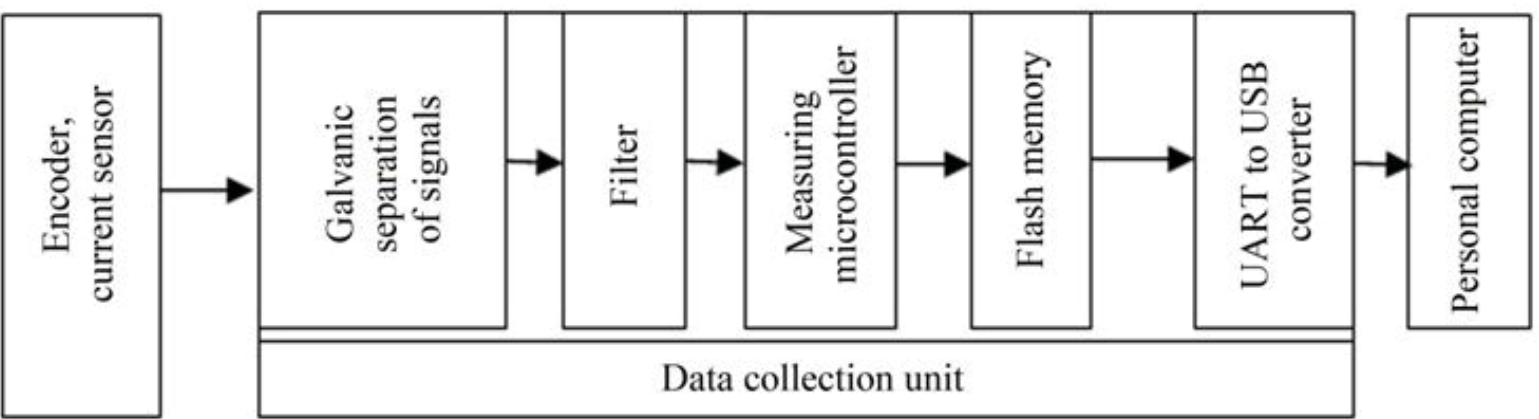

Figure 5: The structure of a data collection unit for identifying the starting torque of an electric actuator for an electromechanical orthosis of a lower limb exoskeleton

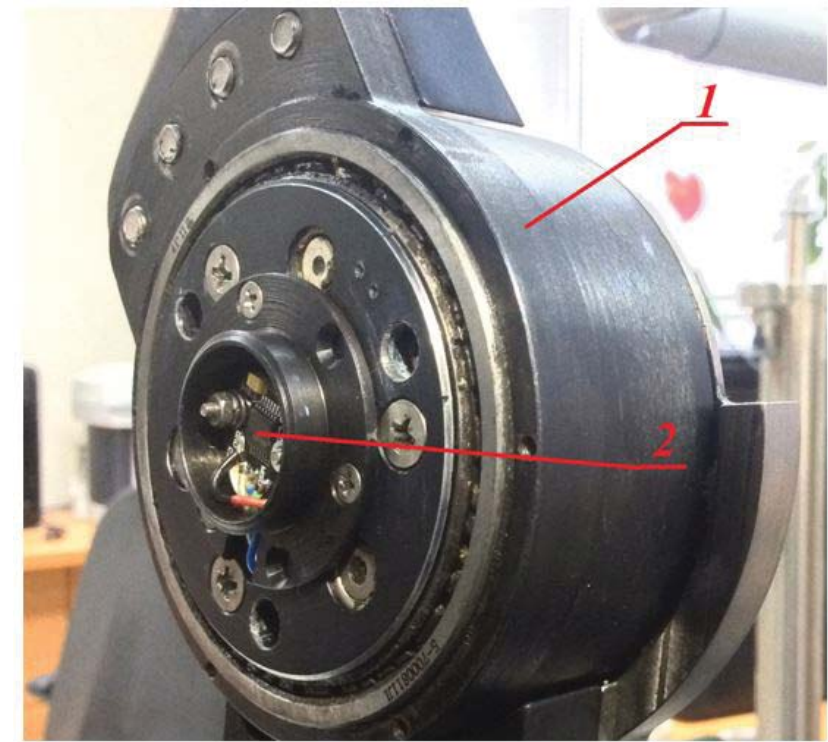

1 is a reducer; 2 is an absolute encoder

Figure 6: General view of a reducer and an absolute encoder for an electromechanical orthosis of a lower limb exoskeleton

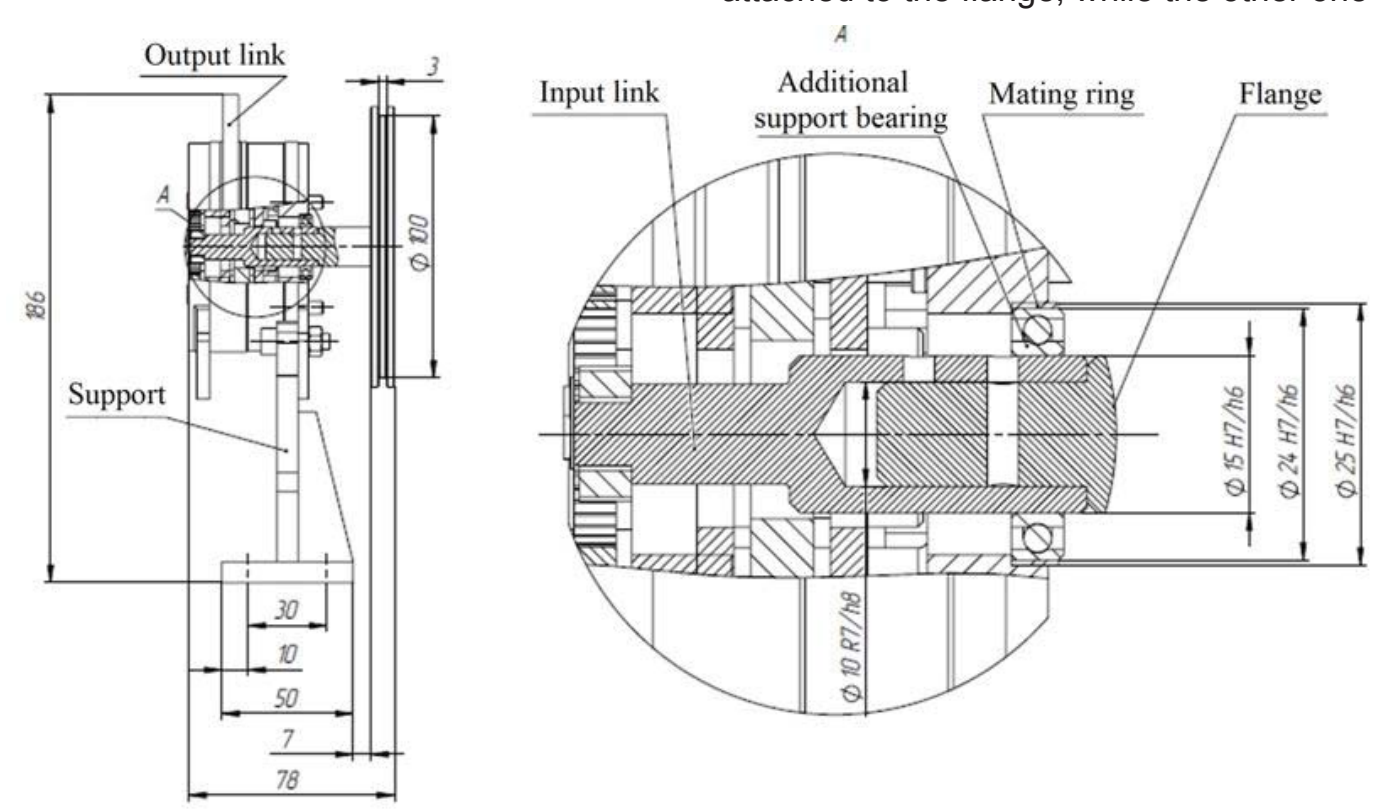

A motor power unit Mean Well HRPG-600-36 is rated for 36 volts DC.

The reducer for an electromechanical orthosis of a lower limb exoskeleton is being developed in the laboratory Mechatronic Systems of the Volga State University of Technology as part of the project called "Creating a hightech production of a multifunctional robotic exoskeleton for medical purposes." These reducers are planetary types of reduction units with involute gearing. Its general view with an absolute encoder is shown in Fig. 6 .

To evaluate the reliability of the data obtained using the developed method and hardware-software complex, a test installation was proposed and assembled, which allowed measuring the starting torque of a reducer for an electromechanical orthosis of a lower limb exoskeleton using an existing method. The scheme of the developed test installation is presented in Fig. 7.

To determine the starting torque of the reducer, the electric actuator was disassembled. The reducer was mounted on a special support. A flange with a diameter of 100 $\mathrm{mm}$ was attached to it. Metal wire with a diameter of 0.3 $\mathrm{mm}$ was wound on the flange. One end of the wire was attached to the flange, while the other one was attached

Figure 7: General view of a test installation for measuring the starting torque of a reducer for an electromechanical orthosis of a lower limb exoskeleton using an existing method 
to a dish for calibrated weights. In the experimental part of this paper, the starting torque values were determined in the initial positions of the flange after every two complete revolutions of it together with an input link of the reducer. The measurements had been carried out until its output link made one complete revolution with the number of the input link revolutions equal to a reduction ratio. Thus, in our case, one revolution of the output link of the reducer with a reduction ratio of 100 corresponds to fifty measurements of the starting torque. The described installation for measuring the starting torque of the reducer with a reduction ratio of 100 is presented in Fig. 8 .

\section{RESULTS AND DISCUSSION}

The goal of the experimental part of this work was to evaluate the reliability of data obtained using the developed method and hardware-software complex for measuring the starting torque of a reducer developed in the laboratory Mechatronic Systems of Volga State University of Technology.

For these purposes, at first, using the developed hardware-software complex, the values of starting torque for various angles of rotation of the reducer input link were determined according to the block diagram presented in Fig. 3. The value of the coefficient characterizing the dependence of its starting torque on its starting current was 109. The values of the starting torque of the reducer for each position of its output link corresponding to two revolutions of its input link were calculated on the basis of experimental data obtained.

Then, measurements of starting torque were carried out for the same positions of the output link of the reducer using the experimental installation presented in Fig. 8.

In the experimental part of this work in the application of the developed method 12 measurements of each angle position of the reducer output link were carried out, blunders were eliminated, random errors were determined and the average values were found.

The values of the starting torque obtained using the developed method (Fig. 3) and the existing one (Fig. 11) are presented in Table 1.

According to the results presented in Table 1, the discrepancy between the starting torque values obtained using the existing method and those obtained using the developed one is within $\pm 1.8 \%$. The presented results show the convergence of data sufficient for applying the developed method and hardware-software complex for evaluating the technical condition of electric actuators and reducers for an electromechanical orthosis of a lower limb exoskeleton both at the stage of their production and during their operation, as well as for further research aimed at the application of the proposed method for assessing electric actuators efficiency and their residual life.

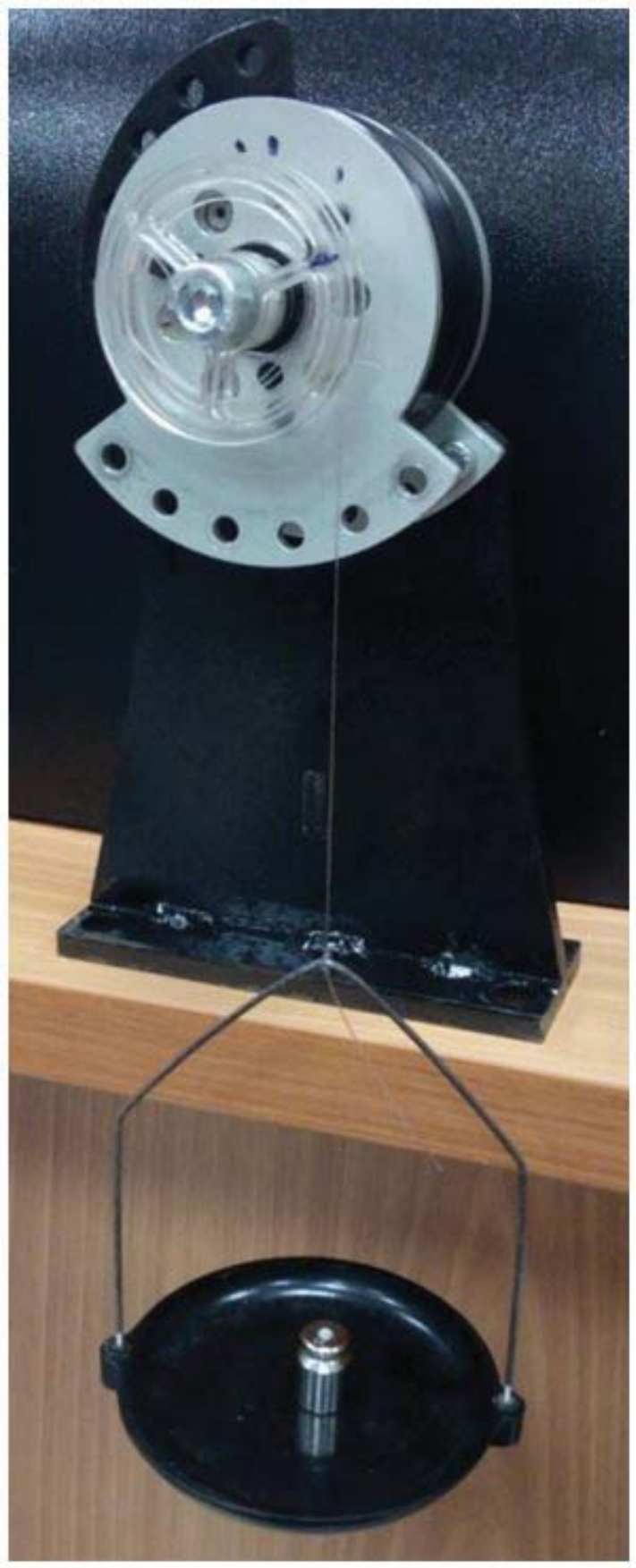

Figure 8: Installation for measuring the starting torque of the reducer with a reduction ratio of 100 using an existing method 
Table 1: Experimental results

\begin{tabular}{|c|c|c|}
\hline $\begin{array}{l}\text { The rotational } \\
\text { angle of the } \\
\text { output link of } \\
\text { the reducer } \\
\text { [degrees] }\end{array}$ & $\begin{array}{l}\text { The starting } \\
\text { torque of the } \\
\text { reducer } \\
\text { obtained using } \\
\text { the existing } \\
\text { method }[\mathrm{N} \cdot \mathrm{m}]\end{array}$ & $\begin{array}{l}\text { The starting } \\
\text { torque of the } \\
\text { reducer } \\
\text { obtained using } \\
\text { the developed } \\
\text { method, [N.m] }\end{array}$ \\
\hline 0 & 0.01225 & 0.01207 \\
\hline 7.2 & 0.04361 & 0.04306 \\
\hline 14.4 & 0.01225 & 0.01229 \\
\hline 21.6 & 0.04312 & 0.04259 \\
\hline 28.8 & 0.01176 & 0.01168 \\
\hline 36 & 0.04361 & 0.04396 \\
\hline 43.2 & 0.01078 & 0.01091 \\
\hline 50.4 & 0.04410 & 0.04432 \\
\hline 57.6 & 0.01225 & 0.01202 \\
\hline 64.8 & 0.04410 & 0.04489 \\
\hline 72 & 0.01176 & 0.01197 \\
\hline 79.2 & 0.04263 & 0.04242 \\
\hline 86.4 & 0.01127 & 0.01112 \\
\hline 93.6 & 0.04263 & 0.04314 \\
\hline 100.8 & 0.01078 & 0.01096 \\
\hline 108 & 0.04263 & 0.04323 \\
\hline 115.2 & 0.01078 & 0.01073 \\
\hline 122.4 & 0.04263 & 0.04295 \\
\hline 129.6 & 0.01127 & 0.01109 \\
\hline 136.8 & 0.04165 & 0.04198 \\
\hline 144 & 0.01078 & 0.01075 \\
\hline 151.2 & 0.04263 & 0.04199 \\
\hline 158.4 & 0.01078 & 0.01095 \\
\hline 165.6 & 0.04361 & 0.04313 \\
\hline 172.8 & 0.01225 & 0.01242 \\
\hline 180 & 0.04361 & 0.04413 \\
\hline 187.2 & 0.01176 & 0.01178 \\
\hline 194.4 & 0.04312 & 0.04269 \\
\hline 201.6 & 0.01078 & 0.01087 \\
\hline 208.8 & 0.04410 & 0.04344 \\
\hline 216 & 0.01225 & 0.01240 \\
\hline 223.2 & 0.04214 & 0.04138 \\
\hline 230.4 & 0.01127 & 0.01147 \\
\hline 237.6 & 0.04263 & 0.04278 \\
\hline 244.8 & 0.01078 & 0.01064 \\
\hline
\end{tabular}

\begin{tabular}{|c|c|c|}
\hline 252 & 0.04165 & 0.04115 \\
\hline 259.2 & 0.01127 & 0.01114 \\
\hline 266.4 & 0.04263 & 0.04203 \\
\hline 273.6 & 0.01127 & 0.01116 \\
\hline 280.8 & 0.0441 & 0.04339 \\
\hline 288 & 0.01176 & 0.01182 \\
\hline 295.2 & 0.04165 & 0.04090 \\
\hline 302.4 & 0.01225 & 0.01240 \\
\hline 309.6 & 0.04410 & 0.04388 \\
\hline 316.8 & 0.01176 & 0.01172 \\
\hline 324 & 0.04263 & 0.04340 \\
\hline 331.2 & 0.01176 & 0.01190 \\
\hline 338.4 & 0.04312 & 0.04334 \\
\hline 345.6 & 0.01225 & 0.01250 \\
\hline 352.8 & 0.04361 & 0.04413 \\
\hline & &
\end{tabular}

\section{CONCLUSIONS}

The results of the presented experimental study indicate the applicability of the developed method for determining the starting torque of an electric gear actuator for an electromechanical orthosis of a lower limb exoskeleton. Evaluation of data obtained using the developed method has shown that the discrepancy between the starting torque values obtained by the existing method and using the developed one is within $1.8 \%$, which is evidence of the efficacy of the proposed approach.

The hardware and software complex developed allows monitoring the starting torque of an electric actuator for an electromechanical orthosis of a lower limb exoskeleton in an automatic mode with lower level of influence of the human factor and with less time and labor costs as compared to existing measuring methods. The use of a built-in encoder of high accuracy for measuring the angle of position of an input shaft of a reducer paves the way towards accelerated assessment of the technical condition of an actuator without the use of additional equipment.

At the technical state control department of a manufacturer, determining the tolerance for changing the starting current of an electric actuator, and also equipping it with a hardware-software complex, it is possible to quickly respond to the deterioration of its efficiency, which allows improving the quality of its assembly, maintaining its high performance, as well as carrying out its timely maintenance and repair.

The described method and instruments can form the basis of indirect methods for determining not only the level of friction in an electric gear actuator, but also its residual life and efficiency without the use of expensive equipment. For these purposes, in further studies it is 
supposed to experimentally identify the dependencies of the starting current of an actuator on its service life and performance, which will make it possible to determine the values of the starting torque at which further operation of the actuator may lead to an unpredictable failure. Those results will allow carrying out maintenance of reducers and electric actuators according to their actual technical condition, adjusting their maintenance schedule and replacement time, and, consequently, increasing the reliability of an exoskeleton.

\section{ACKNOWLEDGEMENT}

The reported study was funded by Ministry of Education and Science of the Russian Federation according to the research project No. 03.G25.31.0261.

\section{REFERENCES}

1. Chen, B., Zhong, C.-H., Zhao, X., Ma, H., Guan, X. \& et al., (2017). A wearable exoskeleton suit for motion assistance to paralysed patients. Journal of Orthopaedic Translation, 11, 7-18. doi:10.1016/j. jot.2017.02.007

2. Chen, B., Ma, H., Qin, L.-Y., Gao, F., Chan, K.-M. \& et al., (2016). Recent developments and challenges of lower extremity exoskeletons. Journal of Orthopaedic Translation, 5, 26-37. doi:10.1016/j. jot.2015.09.007

3. Singla, A., Rupal, B.S., \& Virk, G.S. (2016). Optimization of stepped-cone CVT for lower-limb exoskeletons. Perspectives in Science, 8, 592-595. doi:10.1016/j.pisc.2016.06.030

4. Huysamen, K., Looze, M., Bosch, T., Ortiz, J., Toxiri, S., \& O'Sullivan, L.W.O. (2018). Assessment of an active industrial exoskeleton to aid dynamic lifting and lowering manual handling tasks. Applied Ergonomics, 68, 125-131. doi:10.1016/j.apergo.2017.11.004

5. Kawale, S.S., \& Sreekumar, M. (2018). Design of a Wearable Lower Body Exoskeleton Mechanism for Shipbuilding Industry. Procedia Computer Science, 133, 1021-1028. doi:10.1016/j.procs.2018.07.073

6. Pons, J.L. (2008). Wearable robots: Biomechatronic exoskeletons. Wiley Online Library. doi:10.1002/9780470987667

7. Moreno, J.C., Figueiredo, J., \& Pons, J.L. (2018). Exoskeletons for lower-limb rehabilitation. Colombo R. \& Sanguineti V. (Eds.), Rehabilitation Robotics: Technology and Application. (str. 89-99). Academic Press, Elsevier Inc. doi:10.1016/B978-0-12-8119952.00008-4

8. Gasperini, G., Cannaviello, G., \& Guanziroli, E. (2018). Exoskeleton and end-effector robots for upper and lower limbs rehabilitation: narrative review. PM\&R, 10(9), 174-174. doi:10.1016/j. pmrj.2018.06.005
9. Hassani, W., Mohammed, S., Rifaï, H., \& Amirat, Y. (2014). Powered orthosis for lower limb movements assistance and rehabilitation. Control Engineering Practice, 26, 245-253. doi:10.1016/j.conengprac.2014.02.002

10. Cao, J., Xie, S.Q., Rifaï, H., Das, R., \& Zhu, G.L. (2014). Control strategies for effective robot assisted gait rehabilitation: the state of art and future prospects. Medical Engineering \& Physics, 36(12), 15551566. doi:10.1016/j.medengphy.2014.08.005

11. Majeed, A.P.P.A., Taha, Z., Abidin, A.F.Z., Zakaria, M.A., Khairuddina, I.M., Razman, M.A.M., \& Mohamed, Z. (2017). The control of a lower limb exoskeleton for gait rehabilitation: a hybrid active force control approach. Procedia Computer Science, 105, 183-190. doi:10.1016/j.procs.2017.01.204

12. Tsukahara, A., Kawanishi, R., Hasegawa, Y., \& Sankai, Y. (2010). Sit-to-stand and stand-to-sit transfer support for complete paraplegic patients with robot suit HAL. Advanced Robotics, 24, 1615-1638. doi:10.1163/016918610X512622

13. Anam, K., \& Al-Jumaily, A.A. (2012). Active exoskeleton control systems: state of the art. Procedia Engineering, 41, 988-994. doi:10.1016/j.proeng.2012.07.273

14. Hyun, D.J., Park, H., Ha, T., Park, S., \& Jung, K. (2017). Biomechanical design of an agile, electricity-powered lower-limb exoskeleton for weight-bearing assistance. Robotics and Autonomous Systems, 95, 181-195. doi:10.1016/j.robot.2017.06.010

15. Aliman, N., Ramli, R., \& Haris, S.M. (2017). Design and development of lower limb exoskeletons: A survey. Robotics and Autonomous Systems, 95, 102116. doi:10.1016/j.robot.2017.05.013

16. O'Sullivan, L., Nugent, R., \& der Vorm, J. (2015). Standards for the safety of exoskeletons used by industrial workers performing manual handling activities: a contribution from the robo-mate project to their future development. Procedia Manufacturing, 3, 1418-1425. doi:10.1016/j.promfg.2015.07.306

17. Manna, S.K., \& Dubey, V.N. (2018). Comparative study of actuation systems for portable upper limb exoskeletons. Medical Engineering \& Physics, 60, 1-13. doi:10.1016/j.medengphy.2018.07.017

18. Veale, A.J., \& Xie, S.Q. (2016). Towards compliant and wearable robotic orthoses: A review of current and emerging actuator technologies. Medical Engineering \& Physics, 38(4), 317-325. doi:10.1016/j. medengphy.2016.01.010

19. Long, Y., Du, Z., Chen, C., Wang, W., He, L., \& et al., (2017). Development and analysis of an electrically actuated lower extremity assistive exoskeleton. Journal of Bionic Engineering, 14(2), 272-283. doi:10.1016/S1672-6529(16)60397-9 
20. Egorov, A., Kozlov, K., \& Belogusev, V. (2015). The method and instruments for induction motor mechanical parameters identification. International Journal of Applied Engineering Research, 10(17), 37685-37691.

21. Kotelnets, N., Akimova, N., \& Antonov, M. (2003). Tests, operation and maintenance of electric motors. Moscow: Akademiya.

22. Cipin, R., Mach, M., Toman, M., \& Knobloch, J. (2017). Measurement and evaluation of DC motor starting torque. U: 2017 IEEE International Conference on Environment and Electrical Engineering and 2017 IEEE Industrial and Commercial Power Systems Europe (EEEIC / I\&CPS Europe). doi:10.1109/ EEEIC.2017.7977475

23. Lee, H.J., Im, S.H., Um, D.Y., \& Park, G.S. (2018). A design of rotor bar for improving starting torque by analyzing rotor resistance and reactance in squirrel cage induction motor. IEEE Transactions on Magnetics, 54(3), 1-4. doi:10.1109/TMAG.2017.2764525

24. Sannikov, K. (1948). Calculation of forces and moments in calculating mechanisms. Moscow: GIOP.

25. Yangulov, V. (2008). Accelerated tests of precision reducers for determining their service life. Bulletin of the Tomsk Polytechnic University, 10(2), 28-31.

26. Kondratov, R. (2017). Some updates on calculation of the static torque of a reducer at negative environment temperatures. Intelligent systems in production, 15(2), 31-38. 